\title{
DYNAMICS OF MESHED SPUR GEAR PAIR
}

\author{
Chandan Chattoraj \\ Professor, ME Department, Dr. B. C. Roy Engineering College, Durgapur, West Bengal, India \\ Email: \{chandanchattoraj@yahoo.co.in\}
}

\begin{abstract}
The paper presents a dynamic tooth load analysis of spur gears in mesh. Load sharing characteristics of the analytical model was simulated through a mesh cycle. This model considered the main internal factors of dynamic load as dynamic mesh stiffness. This dynamic load model explored proper integration of contact tooth pairs alternation during mesh cycle. A comparative study is included, which shows the effects of the mechanical properties on the dynamic behaviour of the system.
\end{abstract}

Key words: Spur Gear, Mesh Stiffness, Dynamic loading, Contact ratio.

\section{Introduction}

Gear transmissions are widely used in several industrial applications. Apart from high efficiency, the important criteria for effective operation of these transmissions are low vibration and noise. However, these requirements cannot be satisfied completely. Research on noise and vibration has revealed that the basic mechanism of noise generated from gearing is the gear box vibration excited by the dynamic load. The presence of defects [1] may also alter the normal operating conditions leading to higher vibration levels and a decrease in the efficiency of the transmission.

The dynamic analysis of the gears has become important part due to the pressing need of high speed and heavy load carrying machinery. In these applications, due to high precision, periodic variation of tooth stiffness is the root cause of vibration and noise. A high contact ratio spur gear pairs reduces the variation of tooth stiffness and thus to reduce vibration and noise. Significant improvement in structural efficiency, reliability and power-to-weight ratio is observed. High contact ratio gearing applies to gear meshes that have at least two pairs of teeth in contact at all times i.e. contact ratio of 2 or more. This helps in sharing of transmitted load. In spurgear drives with high contact ratio, the number of contact- teeth-pair is of the order of 2 to 3 . Whereas in spur-gear drives with low contact ratio, design criterion of geartooth is maximum transmitted load. Thus for drives with high contact ratio, load sharing needs to be computed precisely for techno-economical design.

Dynamic response prediction for gear teeth is a major consideration in gear design. In the present paper the dynamic behaviour of a gear pair will be analyzed in context of time varying load/speed conditions through a case study.

\section{Dynamic Model}

Assuming the gear system of the shafts and bearings are rigid, the sliding friction between the tooth surfaces of gear tooth is ignored. Fig.1 shows the dynamic model of gear pair. The teeth of meshing gears are considered as springs and the gear blanks as inertia masses. In developing this model, the dynamic process is studied in the rotating plane of the gears and the differential equations of motion are developed by using the theoretical line of action. In Figure 1, for a pair of contacting teeth, the time-varying mesh stiffness $k_{c}$ together with damping acts as parameter excitations. 


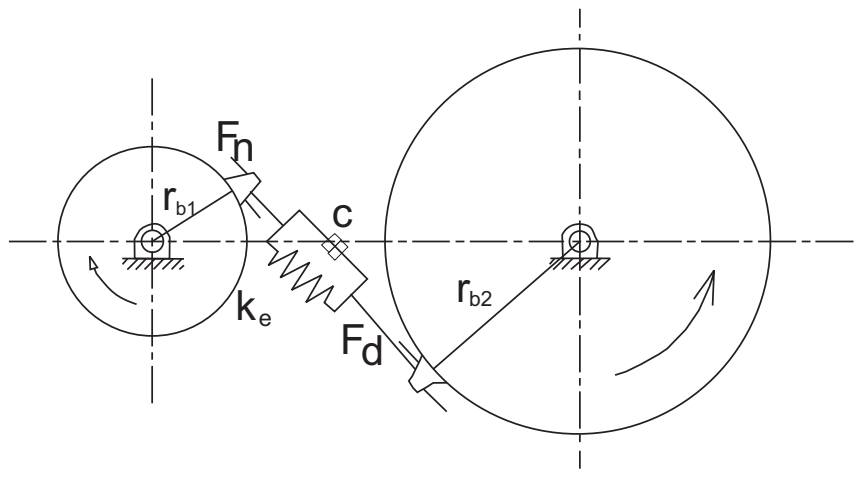

Fig1: Dynamic model of meshing gears

If a tooth of a gear is loaded, the following types of deflection may occur:

(I) The first one is the bending deflection. The tooth is discretized into small section and the bending deflection in this case can be expressed as [1]:

$\delta_{b}=F \cos ^{2} \varphi \sum_{i=1}^{n} e_{i}\left\{\frac{\left(d_{i}-e_{i} d_{i}+\frac{1}{3} e_{i}^{2}\right)}{E I_{i}}+\frac{1}{s G A_{i}}+\frac{\tan ^{2} \varphi}{E A_{i}}\right\}$

Notation:

F- force applied, $\varphi$ - pressure angle, G-shear modulus, sshear factor, $e_{i}$ and $d_{i}$-positions of the different discretized sections with sections area and inertia moments $\mathrm{A}_{\mathrm{i}}$ and $\mathrm{I}_{\mathrm{i}}$; E-Young modulus.

The corresponding bending stiffness of the tooth can be expressed by:

$$
\mathrm{k}_{\mathrm{b}}=\frac{\mathrm{F}}{\delta_{\mathrm{b}}}
$$

(ii) The second tooth deflection is that of the filletfoundation of the tooth. It can be expressed by [2]:

$\delta_{\mathrm{f}}=\frac{\mathrm{F} \cos _{\varphi}^{2}}{\mathrm{bE}}\left\{\mathrm{L}^{*}\left(\frac{\mathrm{u}_{\mathrm{f}}}{\mathrm{s}_{\mathrm{f}}}\right)^{2}+\mathrm{M}^{*}\left(\frac{\mathrm{u}_{\mathrm{f}}}{\mathrm{s}_{\mathrm{f}}}\right)+\mathrm{P}^{*}\left(1+\mathrm{Q}^{*} \operatorname{tg}^{2} \varphi\right)\right\}$

\section{Notation:}

b- tooth width, the coefficients $\mathrm{L}^{*}, \mathrm{M}^{*}, \mathrm{P}^{*}, \mathrm{Q}^{*}$ can be approached by polynomial functions depending on the geometrical characteristics of the gear.
The corresponding fillet-foundation stiffness can be obtained by:

$$
\mathrm{k}_{\mathrm{f}}=\frac{\mathrm{F}}{\delta_{\mathrm{f}}}
$$

(iii) Hertzian deflection is the third deflection occurring for a loaded tooth. It is generally a nonlinear function but can be linearized [3]. The corresponding Hertzian stiffness can be expressed by:

$$
\mathrm{k}_{\mathrm{h}}=\left(\frac{\pi \mathrm{bE}}{41-\mathrm{v}^{2}}\right)
$$

where $v$ is the Poisson ratio of the gear material.

For a gear pair in contact the mesh stiffness $\left(\mathrm{k}_{\mathrm{e}}\right)$ can be obtained by putting in series the different stiffness of the gears:

$$
\mathrm{k}_{\mathrm{e}}=1 /\left(\frac{1}{\mathrm{k}_{\mathrm{b} 1}}+\frac{1}{\mathrm{k}_{\mathrm{b} 2}}+\frac{1}{\mathrm{k}_{\mathrm{f} 1}}+\frac{1}{\mathrm{k}_{\mathrm{f} 2}}+\frac{1}{\mathrm{k}_{\mathrm{h}}}\right)
$$

where suffix 1 is for gear-1 and suffix 2 for gear- 2 .

The contact load varies during the engagement cycle. Occurrences of this variation are mainly due to the following factors:

(i) single and double pair of gear-teeth engaged alternatively;

(ii) dissimilitude of the mesh stiffness along the line of action;

(iii) anomaly of the tooth profile from the theoretical involute profile.

For development of mathematical model with closer resemblance to the physical system, the parameters used in the model need to be estimated correctly.

The equation of motion of the gear pair in mesh is given by,

$$
\mathrm{m}_{\mathrm{e}} \ddot{x}_{\mathrm{d}}+\mathrm{cx}_{\mathrm{d}}+\epsilon \mathrm{F}_{\mathrm{d}}=\mathrm{F}_{\mathrm{n}}
$$

Notation: $\mathrm{m}_{\mathrm{c}}$-equivalent mass of the gear pair, c-damping co-efficient, $\mathrm{F}_{\mathrm{d}}$-dynamic load, $€$-contact ratio, $\mathrm{F}_{\mathrm{n}}$-Static load, $\mathrm{x}_{\mathrm{d}}$-dynamic displacement 
The design parameters of the analyzed gear pair are chosen as (Table-1 and 2):

Table-1: Dimensional parameters

\begin{tabular}{|c|l|l|}
\hline Dimension & Gear 1 & Gear 2 \\
\hline $\mathrm{b}$ & $65 \mathrm{~mm}$ & $65 \mathrm{~mm}$ \\
\hline $\mathrm{m}$ & $6.5 \mathrm{~mm}$ & $6.5 \mathrm{~mm}$ \\
\hline $\mathrm{Z}$ & 25 & 98 \\
\hline $\mathrm{r}_{\mathrm{b}}$ & $100 \mathrm{~mm}$ & $200 \mathrm{~mm}$ \\
\hline $\mathrm{PCD}$ & $230 \mathrm{~mm}$ & $430 \mathrm{~mm}$ \\
\hline$\varphi$ & $20^{\circ}$ & $20^{\circ}$ \\
\hline
\end{tabular}

Notation: b-face width, m-module, Z-no. of teeth, $\mathrm{r}_{\mathrm{b}}$ radius of base circle, $\mathrm{PCD}$-pitch circle diameter,

Table-2: Material properties

\begin{tabular}{|c|c|c|c|}
\hline Property & $\begin{array}{l}\text { Grey CI } \\
\text { (FG 200) }\end{array}$ & $\begin{array}{l}\text { Carbon Steel } \\
(40 C 8)\end{array}$ & $\begin{array}{l}\text { Stainless Steel } \\
\text { (40Cr4Mo2) }\end{array}$ \\
\hline $\mathrm{S}_{\mathrm{ut}}(\mathrm{MPa})$ & $200 \mathrm{MPa}$ & $600 \mathrm{MPa}$ & $800 \mathrm{MPa}$ \\
\hline $\mathrm{E}(\mathrm{GPa})$ & $114 \mathrm{GPa}$ & $200 \mathrm{GPa}$ & $190 \mathrm{GPa}$ \\
\hline $\mathrm{G}(\mathrm{GPa})$ & $46 \mathrm{GPa}$ & $80 \mathrm{GPa}$ & $77 \mathrm{GPa}$ \\
\hline & 0.26 & 0.29 & 0.30 \\
\hline$\rho\left(\mathrm{kg} / \mathrm{m}^{3}\right)$ & 7100 & 7850 & 7800 \\
\hline
\end{tabular}

\section{Results and Discussions}

Graphical solutions of the eqn.(7) are obtained in Scilab v.5.5.2. The material properties of three types of ironbased metals, viz. grey cast iron, carbon steel and stainless steel are considered for comparative study on dynamic behaviour. Amplitude of time-response is markedly decreased with the increase of tensile strength. Higher the strength lesser would be its vibration.

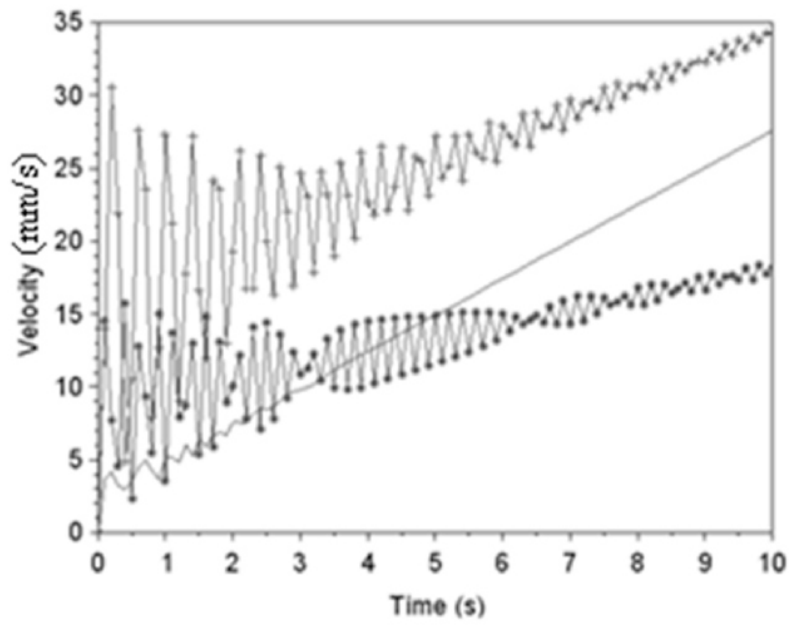

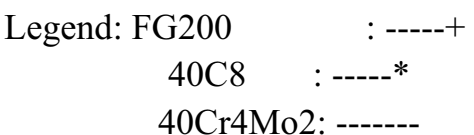

(b)

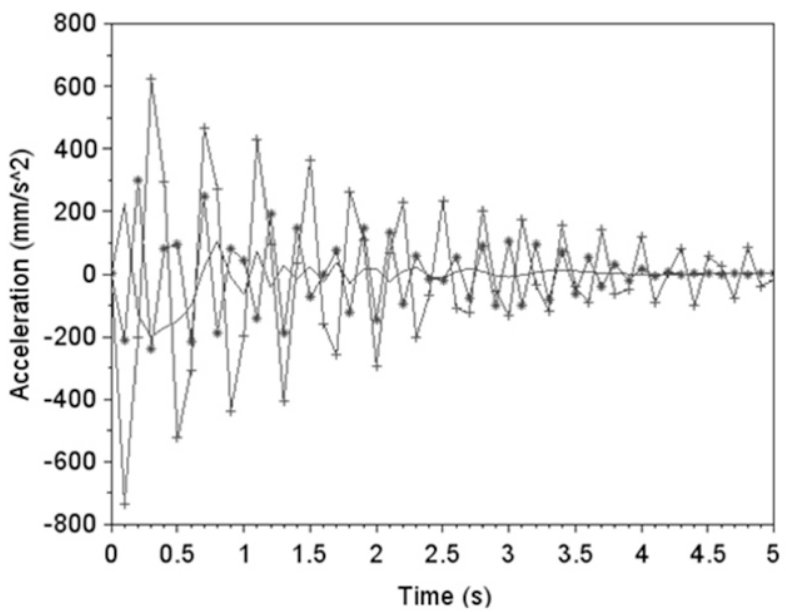

Fig.1(a, b) Time responses of FG200, $40 \mathrm{Cr} 8 \& 40 \mathrm{Cr} 4 \mathrm{Mo} 2$

\section{Conclusions}

A dynamic model of spur gears in mesh shows influence of mesh stiffness on their dynamic behavior. A comparative study is included, which shows the effects of the material properties of three type of iron-based metals, viz. grey cast iron, carbon steel and stainless steel on dynamic response. Dynamic response could be restrained within small value by proper selection of material. The outcome of the present study offers a reference for gear system design. The solution to the problem also provides a reference for inherent characteristic and dynamic response for any gearbox transmission system.

\section{Acknowledgment}

The author is highly indebted to faculty \& staff members of Mechanical Engineering Department, Dr. B. C. Roy Engineering College, Durgapur. 


\section{References}

[1] Cornell R.W., 'Compliance and stress sensitivity of spur gear teeth', ASME J. Mech. Des., 1981, 103, 447-459.

[2] Sainsot P., Velex P., Duverger, O., 'Contribution of gear body to tooth deflections - A new bidimensional analytical Formula', ASME J.Mech. Des., 2004, 126, 748-752.

[3] 'A rotary model for spur gear dynamics', ASME J. Mech., 1985, Trans. Aut. Des. 107, 529-535.

[4] Yang D.C.H., Sun, Z.S., Fatih Karpat et al, 'A Computer Program for Dynamic Load Simulation of Spur Gears with Asymmetric and Symmetric Teeth', World Journal of Mechanics, 2012, 2, 239245 doi:10.4236/wjm.2012.25029.

[5] Ali Kamil jebur et al, 'Numerical and Experimental Dynamic Contact of Rotating Spur Gear', Modern Applied Science, Vol. 5, No. 2, April 2011, doi:10.5539/mas.v5n2p254.

\section{Appendix-I}

Equivalent mass of the gear pair:

$$
\mathrm{m}_{\mathrm{e}}=\mathrm{I}_{1} \mathrm{I}_{2} /\left(\mathrm{I}_{1} \mathrm{r}_{\mathrm{b} 2}^{2}+\mathrm{I}_{2} \mathrm{r}_{\mathrm{b} 1}^{2}\right)
$$

where $I_{1}, I_{2}$ are mass moment of inertia,

$\mathrm{r}_{\mathrm{b} 1}, \mathrm{r}_{\mathrm{b} 2}$ are their base radii.

The damping coefficient can be calculated by

$$
\mathrm{c}=2 \zeta \sqrt{\mathrm{m}_{\mathrm{e}} \mathrm{k}_{\mathrm{e}}}
$$

where $\zeta$ is the damping factor.

The meshing resonance frequency of the gear pair is determined as follows:

$$
\omega_{\mathrm{n}}=\sqrt{\frac{\mathrm{k}_{\mathrm{e}}}{\mathrm{m}_{\mathrm{e}}}}
$$

Static load can be calculated from Lewis equation as follows,

$$
\mathrm{F}_{\mathrm{n}}=\pi \mathrm{y} \cdot \mathrm{b} \cdot \mathrm{m} \cdot \sigma_{\mathrm{b}}
$$

Where b-face width, m-module, $\sigma_{\mathrm{b}}$-bending stress, y-Lewis form factor, Z-no. of teeth. 